\title{
Metabolismo oxidativo de heterófilos de avestruzes jovens
}

\author{
Oxidative metabolism by heterophils from young ostriches
}

\author{
Silvia Cellone Trevelin ${ }^{\mathrm{I}}$ Tatiana de Sousa Barbosa ${ }^{\mathrm{II}}$ Valéria Maria Savoya da Silva ${ }^{\mathrm{III}}$ \\ Paulo César Ciarlini ${ }^{\mathrm{IV}}$
}

RESUMO

Foi avaliada a hipótese que, à semelhança dos neutrófilos de mamíferos, a produção de superóxido pelos heterófilos de avestruzes está associada com a maturidade funcional dessas células. Foram utilizados 20 avestruzes de ambos os sexos, divididos em dois grupos: 1-|30 dias $(n=10) e$ 180-|240 dias $(n=10)$ de idade. Para avaliação do metabolismo oxidativo dos heterófilos, estimou-se a produção de superóxido, utilizando o teste citoquímico não estimulado de redução do tetrazólio de nitroazul (NBT). A porcentagem média de redução heterofílica do NBT de avestruzes com até 30 dias de idade $(0,7 \pm 1,3)$ foi menor $(P<0,001)$ que a observada naqueles com idade entre seis e oito meses $(6,2 \pm 2,7)$. Conclui-se que o metabolismo oxidativo dos heterófilos de avestruzes aumenta com a idade, sugerindo que essa menor produção de superóxido reduz a capacidade bactericida e pode contribuir para a alta mortalidade nos três primeiros meses de vida.

Palavras- chave: imunidade inespecífica, polimorfonuclear, superóxido, nbt, ratita.

\section{ABSTRACT}

It was valuated the hypothesis that, like the neutrophils of mammals, the superoxide production by avian heterophils is associated with functional maturity of these cells. Were used twenty ostriches of both sexes, divided into two groups: 1 -|30 days $(n=10)$ and $180-\mid 240$ days $(n=10)$ of age. The oxidative metabolism by heterophils was estimated by superoxide production in not stimulated cytochemic test of nitroblue terazolium (NBT). The average percentage of heterophilic NBT reduction in ostriches with up to 30 days of age $(0.7 \pm 1,3)$ was lower $(P<0,001)$ than that observed in those aged between six and eight months $(6,2 \pm 2,7)$. It was concluded that the oxidative metabolism by ostriches' heterophils increases with age, suggesting that lower superoxide production reduces the ability bactericide and may contribute to high mortality in the first three moths of life.

Key words: unspecific immunity, polymorphonuclear, superoxide, $n b t$, ratite.

\section{INTRODUÇÃO}

Em 2002, o avestruz (Struthio camelus) foi incluído como ave doméstica pelo Instituto Brasileiro do Meio Ambiente e Recursos Naturais Renováveis (IBAMA, 2008), permitindo a livre criação no território brasileiro, sob fiscalização do Ministério da Agricultura, Pecuária e Abastecimento (MAPA, 2008).

A estrutiocultura apresenta-se em franco crescimento no país. Em 1996, o plantel brasileiro não alcançava 500 avestruzes (ASSOCIAÇÃO DOS EMPREENDEDORES PAULISTAS DE ESTRUTIOCULTURA, 2008). Atualmente, o rebanho nacional aproxima-se de 450 mil aves, o que coloca o Brasil em segundo lugar no ranking mundial, atrás apenas da África do Sul (MUNIZ, 2008; UNIÃO BRASILEIRADE AVICULTURA, 2008).

Apesar de ser um ramo promissor na economia brasileira, a criação de avestruzes ainda enfrenta altas taxas de mortalidade das aves nos

ICurso de Medicina Veterinária, Faculdade de Odontologia (FOA), Universidade Estadual Paulista (UNESP), 16050-680, Araçatuba, SP, Brasil.

IIPrograma de Pós-graduação em Ciência Animal, Curso de Medicina Veterinária, FOA, UNESP, Araçatuba, SP, Brasil. IIIDepartamento de Apoio, Produção e Saúde Animal, Curso de Medicina Veterinária, FOA, UNESP, Araçatuba, SP, Brasil.

${ }^{\text {IV }}$ Departamento de Clínica, Cirurgia e Reprodução Animal, Curso de Medicina Veterinária, FOA, UNESP, Araçatuba, SP, Brasil. Email: ciarlini@fmva.unesp.br. Autor para correspondência. 
primeiros 90 dias de vida. MOTTA et al. (2008) atribuíram à susceptibilidade as infecções bacterianas a maior mortalidade de aves jovens quando verificaram crescimento de Pseudomonas aeruginosa, Escherichia coli (não hemolítica e hemolítica), Klebsiella pneumoniae, Serratia marcescens, Enterobacter aglomerans e Pseudomonas mendocina,em meio de cultura com sangue e amostras provenientes de fígado, pulmão e intestino de 28 avestruzes, incluindo aves que morreram logo após eclosão e com até quatro meses de idade.

Em bovinos, altos índices de mortalidade neonatal por infecção bacteriana também foram observados. COSTA et al. (2004), ao avaliarem a atividade bactericida dos neutrófilos de bezerros da raça holandesa, verificaram que a produção de superóxido aumenta com a idade, atribuindo-se isso à incapacidade dos neutrófilos em responder a estímulos infecciosos nos primeiros dias de vida, tornando os bezerros neonatos mais susceptíveis às infecções.

Nas aves, os heterófilos são leucócitos polimorfonucleares equivalentes aos neutrófilos nos mamíferos e são essenciais para o funcionamento do sistema imunológico inato. Sob estímulo, expressam receptores de membrana responsáveis pela aderência e migração pelo endotélio vascular, dirigindo-se por quimiotaxia ao sítio de infecção. Após fagocitose, há a morte do agente infeccioso por meio de enzimas líticas e agentes oxidantes (RODRÍGUEZ et al., 1997; KOGUT et al., 1998; FARNELL et al, 2003).

Segundo DESMIDT et al. (1996), o heterófilo ativado sofre uma "explosão respiratória”, durante a qual uma grande quantidade de oxigênio molecular é convertida em ânion superóxido por meio do complexo NADPH oxidase. Em mamíferos, o ânion superóxido origina outros compostos altamente reativos, tais como peróxido de hidrogênio $\left(\mathrm{H}_{2} \mathrm{O}_{2}\right)$, íons hidroxila $\left(\mathrm{OH}^{-}\right)$e substâncias halogenadas (BABIOR, 2004). Segundo PENNIALL \& SPITZNAGELL (1975) e HARMON (1998), heterófilos de galinhas são destituídos da enzima mieloperoxidase e incapazes de gerar compostos halogenados, o que tornaria o metabolismo oxidativo dos heterófilos uma linha de defesa secundária aos microrganismos quando comparada à liberação de enzimas lisossomais.

Corroborando uma possível menor importância da geração de reativos derivados de oxigênio na resposta heterofílica das aves em relação aos neutrófilos de mamíferos, CONLON et al.(1991) relataram que heterófilos de galinhas e falcões apresentavam menor produção destes em relação aos neutrófilos isolados de bovinos da raça holandesa. Semelhantemente, BROOKS et al. (1996) e TELL et al.
(1997) verificaram que heterófilos de galinhas e papagaios, respectivamente, produziram menos $\mathrm{H}_{2} \mathrm{O}_{2}$ quando comparados aos neutrófilos de humanos. Não obstante, FARNELL et al. (2003) atribuem grande importância à geração de compostos reativos derivados de oxigênio no combate às infecções nas aves, havendo envolvimento dos receptores toll like dois e quatro, proteína G, proteína quinase C e canais de cálcio.

Segundo CONLON et al. (1991), há divergências entre estudos que analisaram o metabolismo oxidativo dos heterófilos de aves. Essas divergências se devem em parte aos diferentes métodos de análise com sensibilidades distintas, além de diferentes condições experimentais que refletem o grau de ativação dos heterófilos.

DESMIDT et al. (1996) observaram, por meio de quimioluminescência com luminol, que heterófilos isolados de galinha respondiam aumentando a liberação de reativos de oxigênio aos estímulos com phorbol 12-myristate 13-acetate (PMA) e zimosan opsonizado. Em contraponto, KOGUT et al. (2001), utilizando mesmo método, não verificaram tal aumento no metabolismo oxidativo dos heterófilos de galinha frente a esses estímulos.

TELL et al. (1997) e HE et al. (2003; 2007) verificaram em heterófilos de galinhas e papagaios, com o uso de 2,7-dichlorofluorescein diacetate (DCFHDA), aumento na produção de $\mathrm{H}_{2} \mathrm{O}_{2}$ proporcional ao estímulo in vitro com PMA. Diferentemente, outros estudos não detectaram a produção de reativos de oxigênio pelos heterófilos. PENNIALL \& SPITZNAGELL (1975) identificaram falha dos polimorfonucleares de galinha em produzir $\mathrm{H}_{2} \mathrm{O}_{2}$ após a fagocitose, verificada pelo método de oxidação do formato e pela técnica de escopoletina, apesar de constatarem aumento da oxidação da glicose para gerar NADPH frente ao estímulo com $\boldsymbol{S}$. aureus. WIGLEY et al. (1999), por meio da redução do tetrazólio nitroazul (NBT), observaram que heterófilos de galinha, diferentemente dos trombócitos, não produzem superóxido, sugerindo maior importância dos trombócitos na geração de reativos derivados de oxigênio para destruição dos patógenos na espécie.

Até o presente, não há registros sobre o metabolismo oxidativo dos heterófilos de avestruzes e qual o papel destes no combate às infecções dessas aves. Diante da escassez de informação sobre o tema, e considerando a importância zootécnica e econômica dos avestruzes, bem como, o desafio de reduzir a mortalidade juvenil na espécie, propôs-se testar a hipótese que os heterófilos de avestruzes são capazes de gerar radicais de oxigênio e comparar o metabolismo oxidativo desses granulócitos entre avestruzes jovens em diferentes faixas etárias. 


\section{MATERIAL E MÉTODOS}

Foram utilizados 20 avestruzes, de ambos os sexos, com um dia a oito meses de idade, provindos de matrizes de diferentes criatórios da região de Araçatuba, São Paulo (SP), nascidos e criados no setor de Zootecnia do Curso de Medicina Veterinária da Faculdade de Odontologia (FOA) da Universidade Estadual Paulista (UNESP). Considerou-se como critério de inclusão a boa condição clínica e corpórea no momento da colheita e após 30 dias.

$\mathrm{O}$ arraçoamento (Ração para avestruzes Êxito Rural ${ }^{\circledR}$, Nutrição de ruminantes ltda, AraçatubaSP) e fornecimento de água às aves foram ad libitum, sendo o primeiro com uso de rações para avestruzes destinadas à fase inicial e de crescimento.

Logo após o nascimento, as aves foram identificadas, pesadas, sexadas e submetidas à desinfecção do umbigo com solução alcoólica de clorexidina $2 \%$, durante três dias consecutivos. Os recém-nascidos permaneceram na sala da maternidade por cinco dias, alojados em gaiolas retangulares e com aquecimento elétrico automático $\left( \pm 29^{\circ} \mathrm{C}\right)$, recebendo ração inicial. As aves com idade entre 5-|30 dias foram mantidas em galpão de alvenaria, contendo seis boxes equipados individualmente com abrigos noturnos e aquecimento elétrico automático $\left(+29^{\circ} \mathrm{C}\right)$. Receberam ração inicial e folhas de amora picadas (uma vez ao dia) e tiveram acesso ao pasto de amendoim forrageiro (Arachis pintoi). Os avestruzes com 180-|240 dias foram alojados em piquetes agrupados em forma de pizza com acesso a pasto de braquiária (Braquiaria decumbens) e alimentados com ração de crescimento.

As aves foram separadas em dois grupos de acordo com a faixa etária: 1-|30 dias (n=10) e 180-|240 dias $(n=10)$ de idade. Amostras de sangue total heparinizadas $\left(10 \mathrm{U} \mathrm{ml}^{-1}\right)$ foram coletadas da veia jugular das aves com até trinta dias de idade e da veia subcutânea ulnar das demais, assim como preconizado por LUMEIJ (1997). Seguindo as recomendações de DEIN (1996), capuzes foram utilizados nas aves para minimizar o estresse da contenção e colheita. O sangue foi mantido em recipiente isolado termicamente para o transporte até o laboratório, por, no máximo, 30 minutos.

A produção de superóxido pelos heterófilos foi estimada pelo teste de redução do tetrazólio de nitroazul (NBT, Sigma-Aldrich, St. Louis, USA) não estimulado. O teste de redução foi realizado pelo método citoquímico descrito por CIARLINI et al. (2005). Em resumo, $25 \mu \mathrm{l}$ de sangue foi adicionado à mesma quantidade de NBT $\left(1 \mathrm{mg} \mathrm{ml}^{-1}\right)$ e incubado a $37^{\circ} \mathrm{C}$, durante 15 minutos, seguindo-se de 15 minutos em temperatura ambiente. A porcentagem de células redutoras de NBT foi estabelecida a partir da contagem de 100 heterófilos.

Para as comparações entre os grupos experimentais, foi utilizado o teste não paramétrico Mann-Whitney em programa estatístico computadorizado (Software, Statistical Analysis System Institute, 1997, USA).

\section{RESULTADOS E DISCUSSÃO}

Os heterófilos de todos os avestruzes com idade entre seis e oito meses reduziram o NBT (Figura 1), comprovando que são capazes de gerar metabólitos do oxigênio, assim como verificado por DESMIDT et al. (1996), FARNELL et al. (2003) e HE et al. (2003 e 2007), em heterófilos de galinhas, RODRÍGUEZ et al. (1997), em pombos da espécie Streptopelia risória, e TELL et al. (1997), em papagaios Amazona amazonica amazonica. Não foram encontrados na literatura dados similares em relação aos avestruzes.

O único estudo sobre metabolismo oxidativo dos hetrófilos em aves que utilizou o método de redução do NBT (WIGLEY et al. 1999) não detectou produção de superóxido em galinhas. A discordância quanto à redução do NBT pelos heterófilos observada por WIGLEY et al. (1999) pode ter relação com a exposição das aves à luz, porque as amostras foram coletadas no período de verão, em país de clima tropical, enquanto WIGLEY et al. (1999) analisaram galinhas criadas em país de clima temperado, portanto, com menor incidência luminosa. Segundo RODRÍGUEZ et al. (1997) e TERRÓN et al. (2003), a melatonina, produzida pela glândula pineal sob ausência de estímulo luminoso, exerce efeito inibitório sob o metabolismo oxidativo de pombos da espécie Streptopelia risoria. O método quantitativo de redução do NBT utilizado por WIGLEY et al. (1999), embora mais sensível que o citológico, requer isolamento celular, o que pode comprometer o funcionamento do heterófilo de modo a não detectar a produção de superóxido à semelhança do presente estudo. Portanto, tal divergência entre o metabolismo oxidativo dos avestruzes e das galinhas parece não ser restrita a particularidades das espécies, uma vez que a produção de superóxido em galinhas já foi comprovada em estudos que utilizaram outras metodologias (DESMIDT et al. 1996; FARNELL et al. 2003, HE et al. 2003; 2007).

As divergências entre estudos que analisaram o metabolismo oxidativo dos heterófilos de aves devem-se em parte às diferentes metodologias com sensibilidades distintas. A quimioluminescência com luminol utilizada por DESMIDT et al. (1996) mensura todos os metabólitos de oxigênio, enquanto a 


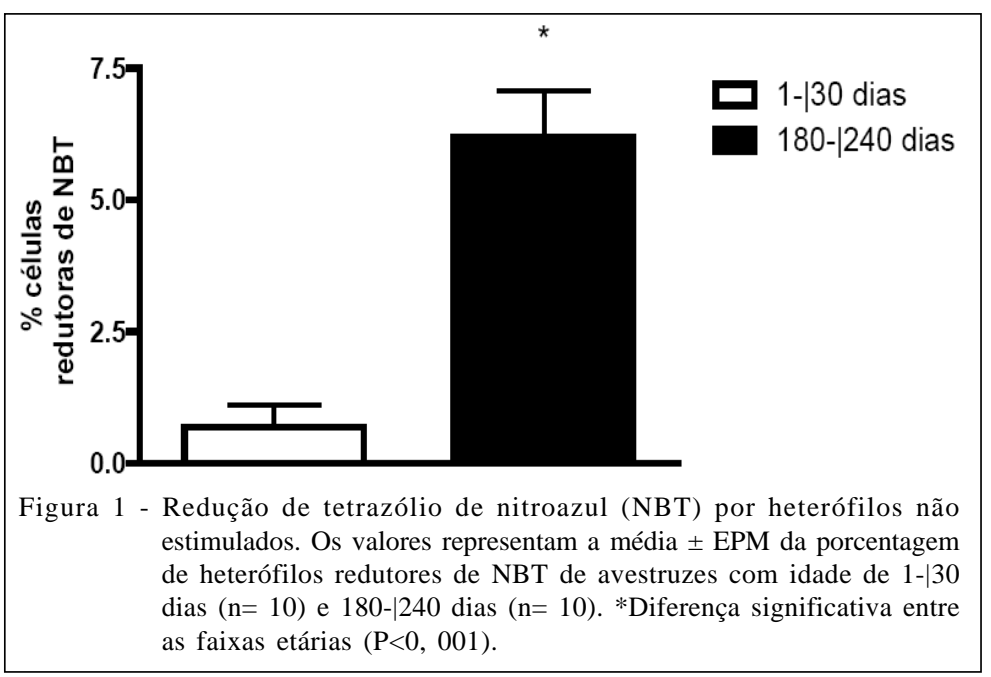

anormalidades na ativação do complexo enzimático NADPH oxidase, deficiência da enzima glicose-6-fosfatodesidrogenase e atividade anormal ou deficiente da proteína quinase $\mathrm{C}$. O resultado pode estar relacionado à alta mortalidade dos avestruzes nos primeiros 90 dias de vida (MOTTA et al., 2008), quando a menor geração de reativos derivados de oxigênio tornaria as aves nessa faixa etária mais susceptíveis à infecção.

Apesar de os heterófilos nas aves serem a principal linha de defesa contra os microrganismos, em situações de estresse, há redução da atividade fagocitária (SPINU et

citometria de fluxo com DCFH-DA utilizada por TELL et al. (1997) e HE et al. (2003; 2007) avalia principalmente o peróxido de hidrogênio. O tetrazólio de nitroazul é um corante supravital amarelo claro que sofre redução na presença do ânion superóxido, tornando-se azul escuro. Constitui um método rápido, simples, que não requer isolamento celular e apresenta baixo custo para avaliação do metabolismo oxidativo dos fagócitos (GORDON et al., 1973).

Ao se compararem os resultados que utilizaram a mesma metodologia adotada no presente estudo, observou-se que a média de redução do NBT, em avestruzes entre seis e oito meses de idade $(6,2 \%)$, foi inferior à média de redução de NBT de cães (CIARLINI et al., 2004), enquanto a média observada em aves com até trinta dias $(0,7 \%)$ assemelha-se à observada em bovinos por CIARLINI et al. (2005). Segundo CONLON et al. (1991), bovinos apresentam maior produção de reativos derivados de oxigênio que galinhas e falcões devido à maior área de superfície dos neutrófilos comparada à área dos heterófilos nas espécies avaliadas, o que é corroborado por ROBINSON et al. (2004), ao observarem que a produção de $\mathrm{H}_{2} \mathrm{O}_{2}$ ocorre em toda superfície dos neutrófilos, além do vacúolo fagocítico. Tomando-se tais prerrogativas, talvez a superfície do heterófilo de avestruzes adultos seja menor que a de cães e a dos pintainhos se assemelhe a de bovinos.

Os avestruzes com até 30 dias de vida apresentaram menor capacidade de redução do NBT $(\mathrm{P}<0,001)$ quando comparados às aves com idade entre seis e oito meses (Figura 1), à semelhança do observado em bezerros por COSTA et al. (2004). Possíveis explicações para a falha do mecanismo de produção do ânion superóxido nos avestruzes 1-|30 dias incluem al.,1999). Os avestruzes analisados foram criados em cativeiro e, dessa forma, foram submetidos a estresse contínuo, podendo possuir resposta oxidativa diferente daqueles criados em vida livre.

Há necessidade de se investigar qual o efeito do estresse causado pelo cativeiro, assim como a influência do fotoperíodo sobre o metabolismo oxidativo dos heterófilos de avestruzes e sua relação com a alta mortalidade juvenil da espécie.

\section{CONCLUSÃO}

A geração de superóxido pelos heterófilos de avestruzes aumenta com a idade, e a menor capacidade de redução do NBT coincide com a faixa etária em que ocorre a maior taxa de mortalidade na espécie. A falha na produção de superóxido pode estar relacionada à morte precoce dos avestruzes. Para sugerir formas de reduzir tal parâmetro, são necessárias investigações acerca do prejuízo suplementar do fotoperíodo negativo e cativeiro sobre a produção de reativos de oxigênio pelos heterófilos.

\section{AGRADECIMENTOS}

À Fundação de Apoio à Pesquisa do Estado de São Paulo (FAPESP), pela bolsa auxílio (processo 06/50945-8), ao Médico Veterinário Antônio José Sabino, à Prof ${ }^{\text {a. }}$ Dra. Maria Margareth Theodoro Caminhas (Unesp/Araçatuba), ao Prof. Dr. Manoel Garcia Neto (Unesp/Araçatuba), à UNEAVESTRUZ e à Associação Brasileira deEstrutiocultura (ABRE).

\section{REFERÊNCIAS}

ASSOCIAÇÃO DOS EMPREENDEDORES PAULISTA DA ESTRUTIOCULTURA. Mercado interno: agronegócio. Acessado em 10 jun. 2008. Online. Disponível em: http://

Ciência Rural, v.39, n.7, out, 2009. 
www.aepe.com.br/?md=cstatic\&page=estrutiocultura/ agronegocio/ mercadoin.

BABIOR, B.M. NADPH oxidase. Current Opinion in Immunology, v.16, n.1, p.42-47, 2004. Disponível em: <http://www.sciencedirect.com/ science?_ob=ArticleURL\&_udi=B6VS1-4B 7 Y PKX$6 \&$ \&user $=5674931 \&$ \&doc $=1 \&$ _fmt $=$ \&_orig=search\&_sort $=$ d\&vie $\mathrm{w}=$ c \&_a c c t $=$ C $000049650 \&$ \& version $=1 \&$ \&_url Ve rsion=0\&_userid=5674931\&md5=93f87d38ebf68783761951c65992fd34>. Acesso em: 14 abril 2009. doi:10.1016/j.coi.2003.12.001.

MAPA. Ministério da Agricultura, Pecuária e Abastecimento. Gabinete do Ministro, Instrução Normativa $n^{0} 56$ de 4 de dezembro de 2007. Estabelece os Procedimentos para Registro, Fiscalização e Controle de Estabelecimentos Avícolas de Reprodução e Comerciais. Acesso em: 30 jun. 2008. Online. Disponível em: http://extranet.agricultura.gov.br/sislegis-consulta/ consultarLegislacao.do?operacao=visualizar\&id=18261

IBAMA. Instituto Brasileiro do Meio Ambiente e Recursos Naturais Renováveis. Presidente do IBAMA, Portaria no 36 de 15 de março de 2002. Inclui a avestruz-africana, Struthio camellus, no Anexo 1 da Portaria IBAMA n 93/98, de 07 de julho de 1998, que contém a listagem de fauna considerada doméstica para fins de operacionalização do IBAMA. Acesso em: 30 jun. 2008. Online. Disponível em: http:// www.ibama.gov.br/cnia/index.php?id_menu=66.

BROOKS, J.R.L. et al. Functional comparison of avian heterophils with human and canine neutrophils. Comparative Haematology International, v.6, n.3, p.153-159, 1996. Disponível em: <http://www.springerlink.com/content/ w3kkuqp528753833/>. Acesso em: 14 abril 2009. doi: 10.1007/ BF00368459.

CIARLINI, P.C. et al. Efeito da vacina contra brucelose bovina sobre a capacidade neutrofílica de redução do NBT. ARS Veterinária, v.21, n.2, p.251-256, 2005. Disponível e m : < h t t p : / / b v s . pan a f tos a.org.br/t ext oc ciarlini_efeito_da_vacina_contra_brucelose_bovina.pdf.>. Acesso em: 14 abril 2009.

CIARLINI, P.C. et al. Efeito da vacina polivalente sobre o leucograma e o metabolismo oxidativo dos neutrófilos em cães. Arquivos do Instituto Biológico, v.71, n.3, p.323-327, 2004 Disponível em: <http://www.biologico.sp.gov.br/docs/arq/V71_3/ ciarlini.pdf $>$. Acesso em: 14 abril 2009.

CONLON, P. et al. Oxygen radical production by avian leukocytes. Canadian Journal of Veterinarian Research, v.55, n.2, p.193-195, 1991. Disponível em: <http:// www.pubmedcentral.nih.gov/articlerender.fcgi?artid=1263442>. Acesso em: 14 abril 2009.

COSTA, J.N. et al. Influência do desenvolvimento etário e da suplementação com vitamina E (acetato de DL-alfatocoferol) no metabolismo oxidativo dos neutrófilos de bovinos da raça holandesa (Bos taurus). Brazilian Journal of Veterinary Research and Animal Science, v.41, n.5, p.293-298, 2004. Disponível em: <http://www.scielo.br/scielo.php?pid=S1413$95962004000500001 \&$ script $=$ sci_arttext\&tlng $=p t>$. Acesso em: 14 abril 2009. doi: 10.1590/S1413-95962004000500001.

DEIN, F.J. Hematology. In: HARRISON, G.J.; HARRISON, L.R. Clinical avian medicine and surgery. Philadelphia: Saunders, 1996. Cap.12, p.175-189.
DESMIDT, M. et al. Oxygenation activity of chicken blood phagocytes as measured by luminol- and lucigenin- dependent chemiluminescence. Veterinary Immunology and Immunopathology, v.53, n.3-4, p.303-311, 1996. Disponível em: <http://www.sciencedirect.com/ science?_ob=ArticleURL\&_udi=B6TD5-3W2XM60B\&_user=5674931\&_rdoc $=1 \&$ \&mt=\&_orig=search\&_sort=d\&view= c \&_a c c t $=$ C $000049650 \&$ \&_version $=1 \&$ \&_url Versi on $=0$ \& userid $=5674931 \&$ md5=7f25e6b70f8492a1ca57b67905049342>. Acesso em: 14 abril 2009. doi: 10.1016/S0165-2427(96)05620-6.

FARNELL, M.B. et al. Differential activation of signal transduction pathways mediating oxidative burst by chicken heterophils in response to stimulation with lipopolysaccharide and lipoteichoic acid. Inflammation, v.27, n.4, p.225-231, 2003. Disponível em: <http://www.springerlink.com/content/ 14361x2q127r1595/>. Acesso em: 14 abril 2009. doi: 10.1023/ A: 1025088514676 .

GORDON, A.M. et al. Routine application of the nitrobluetetrazolium test in the clinical laboratory. Journal of Clinical Pathology, v.26, p.52-56, 1973.

HARMON, B.G. Avian heterophils in inflammation and disease resistance. Poultry Science, v.77, n.7, p.972-977, 1998. Disponível em: <http://ps.fass.org/cgi/reprint/77/7/972 >. Acesso em: 14 abril 2009.

$\mathrm{HE}, \mathrm{H}$. et al. Inflammatory agonist stimulation and signal pathway of oxidative burst in neonatal chicken heterophils. Comparative Biochemistry and Physiology, v.135, n.1, p.177-184, 2003. Disponível em: <http://www.sciencedirect.com/ science?_ob=ArticleURL\&_udi=B6VNH-48B0T4P$18 \_u s e r=5674931 \& \_r d o c=1 \& \_f m t=\&$ orig $=$ search\&_sort $=\mathrm{d} \&$ view $=$ c \&_a c c t = C 000049650 \&_version $=1 \&$ \&_url Ve rsion=0\&_userid=5674931\&md5=7e1d37375348955ae478fd0248529e66> . Acesso em: 14 abril 2009. doi:10.1016/S1095-6433(03)00049-7.

$\mathrm{HE}, \mathrm{H}$. et al. In vivo priming heterophil innate immune functions and increasing resistance to Salmonella enteritidis infection in neonatal chickens by immune stimulatory CpG oligodeoxynucleotides. Veterinary Immunology and Immunopathology, v.117, n.3-4, p.275-283, 2007. Disponível em: <http://www.sciencedirect.com/ science?_ob=ArticleURL\&_udi=B6TD5-4N919J12\&_user $=5674931 \&$ _rdoc $=1 \&$ \& $\mathrm{fmt}=$ \&_orig $=$ search\&_sort $=\mathrm{d} \& \mathrm{vie}$ w = c \&_a c c t = C $000049650 \&$ \& versio n $=1 \&$ \&_u rlVersion=0\&_userid=5674931\&md5=2dd077b7138274777620a22cc11327c0>. Acesso em: 14 abril 2009. doi:10.1016/j.vetimm.2007.03.002.

KOGUT, M.H. et al. Lymphokine-augmented activation of avian heterophils. Poultry Science, v.77, n.7, p.964-971, 1998. Disponível em: <http://ps.fass.org/cgi/content/abstract/ 77/7/964>. Acesso em: 14 abril 2009.

KOGUT, M.H. et al. Modulation of functional activities of chicken heterophils by recombinant chicken IFN-g. Journal of Interferon and Cytokine Research, v.21, n.2, p.85-92, 2001. Disponível em: http://www.liebertonline.com/doi/pdf/ $10.1089 / 107999001750069944$ ?cookieSet=1>. Acesso em 14 abril 2009.

LUMEIJ, J.T. Avian clinical biochemistry. In: KANEKO, J.J. et al. Clinical biochemistry of domestical animals. 5.ed. San Diego: Academic, 1997. Cap.30, p.857-883. 
MOTTA, O.V. et al. Diagnóstico microbiológico e histopatológico de mortalidade em avestruzes (Struthio camelus). Arquivo Brasileiro de Medicina Veterinária e Zootecnia, v.60, n.4, p.1014-1016, 2008. Disponível em: $<$ ht tp: / / www.scielo.br/scielo.php?pid=S 0102 09352008000400034\&script=sci_arttext $>$. Acesso em: 14 abril 2009. doi: 10.1590/S0102-09352008000400034.

MUNIZ, L.R. Mercado: a indústria do avestruz no Brasil. ASSOCIAÇÃO DOS CRIADRES DE AVESTRUZ DO BRASIL. Acesso em 15 jul. 2008. Online. Disponível em:<http:// www.acab.org.br/?ac=ler\&id=888>.

PENNIALL, R.; SPITZNAGEL, J.K. Chicken neutrophils: oxidative metabolism in phagocytic cells devoid of myeloperoxidase. Proceedings of National Academic Science, California, v.72, n.12, p.5012-5015, 1975. Disponível em: <http:/ /www.pubmedcentral.nih.gov/articlerender.fcgi?artid=388865 >. Acesso em 14 abril 2009.

UNIÃO BRASILEIRA DE AVICULTURA. Relatório anual da união brasileira de avicultores 2007/2008. Estrutiocultura: foco na exportação. Disponível em:<http://www.uba.org.br/ubarel08-internet.pdf.>. Acesso em: 19 jul. 2008.

ROBINSON, J.M. et al. Regulation of the NADPH-oxidase complex of phagocytic leukocytes: recent insights from structural biology, molecular genetics, and microscopy. Histochemical Cell Biology, v.122, n.4, p.293-304, 2004.

RODRÍGUEZ, A.B. et al. Melatonin and the phagocytic process of heterophils from the ring dove (Streptopelia risoria).
Molecular and Cellular Biochemistry, v.168, n.1-2, p.185190, 1997. Disponível em: <http://www.springerlink.com/ content/l8q6855181823087/>. Acesso em: 14 abril 2009. doi: 10.1023/A:1006850518225.

SPINU, M. et al. Haematological and immunological variables in a domesticated and wild subspecies of ostrich (Struthio camelus). British Poultry Science, v.40, n.5, p.613-618, 1999. Disponível em: <http://www.isrvma.org/article/ 60_4_3.htm >. Acesso em: 14 abril 2009.

TELL, L.A. et al. Flow cytometric quantitation of oxidative product formation by heterophils from orange-winged Amazon parrots (Amazona amazonica amazonica). Comparative Clinical Pathology, v.7, n.4, p.197-201, 1997. Disponível em: <http://www.springerlink.com/content/w323351422qpt664/>. Acesso em: 14 abril 2009. doi: 10.1007/BF02658689.

TERRÓN, M.P. et al. Phagocitosis of Candida albicans and superoxide anion levels in ring dove (Streptopelia risoria) heterophils: effect of melatonin. Journal of Neuroendocrinology, v.15, n.12, p.1111-1115, 2003. Disponível em: <http://www3.interscience.wiley.com/journal/ 118888818/abstract?CRETRY $=1 \&$ SRETRY $=0>$. Acesso em: 14 abril 2009. doi: 10.1111/j.1365-2826.2003.01103.

WIGLEY, P. et al. Phagocytic and oxidative burst activity of chicken thrombocytes to Salmonella, Escherichia coli and other bacteria. Avian Pathology, v.28, n.6, p.567-572, 1999. Disponível em: <http://www.informaworld.com/smpp/ content $\sim$ content $=\mathrm{a} 713651120 \sim \mathrm{db}=$ all $\sim$ order $=$ page $>$. Acesso: em 14 abril 2009. doi: 10.1080/03079459994353. 